\title{
Pathogen profile and MMP-3 levels in areas with varied attachment loss in generalized aggressive and chronic periodontitis
}

\author{
MUSTAFA YILMAZ ${ }^{1}$, GÖKHAN KASNAK ${ }^{2}$, NURAY G. POLAT ${ }^{3}$, NURSEN E. TOPCUOGLU 4 , \\ GÜVEN KÜLEKCI ${ }^{4}$ ERHAN FIRATLI ${ }^{2}$ \\ ${ }^{1}$ Department of Periodontology, Biruni University, Istanbul, Turkey \\ ${ }^{2}$ Department of Periodontology, Faculty of Dentistry, Istanbul University, Istanbul, Turkey \\ ${ }^{3}$ Virology and Fundamental Immunology Unit, Faculty of Medicine, Istanbul University, Istanbul, Turkey \\ ${ }^{4}$ Department of Microbiology, Faculty of Dentistry, Istanbul University, Istanbul, Turkey
}

\begin{abstract}
Introduction: The progression of periodontitis depends on the changes in bone and connective tissue homeostasis and the imbalance of the biofilm and the host immunoinflammatory response, particularly matrix metalloproteinases (MMP).

Aim of the study: To assess the probable relation between subgingival anaerobic flora and the expression of MMP-3 in patients with generalized aggressive periodontitis $(A g P)$, chronic periodontitis $(C P)$ and healthy subjects, and to evaluate these levels according to varied tissue loss severity.

Material and methods: The plaque index (PI), gingival index (GI), probing depth (PD) and clinical attachment levels (CAL) were evaluated. MMP levels obtained from gingival sulcus fluid $(G C F)$ were measured with Enzyme Linked Immuno Assay (ELISA). The bacterial counts were determined with Parocheck $^{\circledR}$.

Results: Higher levels of MMP-3 in patients with AgP compared to subjects with $C P$ and healthy individuals were observed. The microorganisms responsible of possible tissue destruction in both AgP and $C P$ are red complex bacteria. T. denticola, T. forsythia, $P$. intermedia and $F$. nucleatum show positive correlation with MMP-3 levels.

Conclusions: $M M P-3$ is a biomarker associated with $\mathrm{AgP}$, and red complex bacteria levels are correlated with increasing periodontal tissue loss in both periodontitis forms. The diagnosis of aggressive periodontitis, or site-specific treatment strategies can be orchestrated based on the evaluation of $M M P-3$ and the bacterial counts in patients with periodontitis.
\end{abstract} fluid.

Key words: MMP, pathogens, aggressive periodontitis, chronic periodontitis, gingival crevicular

(Centr Eur J Immunol 2019; 44 (4): 440-446)

\section{Introduction}

Periodontitis occurs as a result of disrupted homeostasis and periodontal tissue injury, which is provoked by the inflammatory response to commensal microorganisms found in dental biofilm [1]. The severity of the disease is characterized by the level of connective tissue degradation, pocket formation and bone loss. The disease progresses mainly in molars and interproximal areas, especially in areas with higher probing depth [2].

$A$. actinomycetemcomitans, $P$. gingivalis, $P$. intermedia, T. forsythia, F. nucleatum and $P$. micros are the most significant markers for tissue loss [3] and in periodontal pockets with higher probing depth, more anaerobic activity is observed [4]. These bacteria stimulate the proliferation of circulating immune cells and the production of proinflammatory cytokines, prostaglandins and proteases. Among these, the fundamental molecules for extracellular matrix degradation and remodeling are matrix metalloproteinases (MMPs) [5]. MMPs are divided into several subgroups: collagenases (MMP-1, -8, -13, -18), gelatinases (MMP-2, -9), stromelysins (MMP-3, -10, -11), membrane type MMPs (MMP-14, -15, $-16,-17,-24)$, and others.

MMP-3 (stromelysin 1) is essential for activating proMMPs, e.g. to process proMMP-1 to fully activate MMP-1, and to digest a wide variety of extracellular matrix molecules [6].

Our aim was to evaluate and compare the levels of certain pathogenic bacteria and MMP-3 in patients with chronic

Correspondence: Asst. Prof. Mustafa Yılmaz, Department of Periodontology, Biruni University, 10. Y1l Caddesi Protokol Yolu No: 45, 34010 Topkap1 / Istanbul, Turkey, e-mail: dtyilmazmustafa@gmail.com Submitted: 15.02.2018; Accepted: 14.05.2018 
periodontitis $(\mathrm{CP})$, aggressive periodontitis $(\mathrm{AgP})$ or patients without any bone or attachment loss and compare the difference of these levels according to the clinical attachment loss severity and probing depth of the same individuals.

\section{Material and methods}

\section{Subjects}

Twenty non-smoking, untreated patients with generalized aggressive periodontitis, 20 patients with chronic periodontitis, and a control group of 10 periodontally healthy subjects were evaluated. None of the participants had any systemic disease, and in the six months leading up to the sample collection, none of them were prescribed any antibiotics or anti-inflammatory medicine.

\section{Clinical evaluation}

The individuals were diagnosed clinically and radiographically as defined by the American Academy of Periodontology [7]. The following criteria were measured with a Williams type probe for determining each subject's periodontal status:

plaque index (PI) [8],

gingival index (GI) [9],

probing depth (PD),

clinical attachment level (CAL).

\section{Collection of gingival crevicular fluid}

Collection of gingival crevicular fluid (GCF) samples were collected from 90 sites in 20 individuals with AgP and 20 individuals with CP. In each patient, samples were collected from at least one site with severe periodontal tissue destruction from the patient's deepest pocket (CAL and $\mathrm{PD} \geq 5 \mathrm{~mm}$ ) (AgP_D, CP_D) and from at least one site with no attachment loss (PD $\leq 3 \mathrm{~mm})($ AgP_H, CP_H $)$. In the control group, 10 samples were taken in total from a random crevice of each periodontally healthy individual.

In addition, 10 of the $\mathrm{AgP}$ and 10 of the $\mathrm{CP}$ patients were included in a microbiological evaluation. One sample from a periodontally diseased and one sample from a healthy site were obtained from each patient.

Samples of GCF were collected with periopapers (PROFLOW Inc. NY, USA). These strips were put into Eppendorf Tubes separately, and these tubes were labeled and weighed before and after GCF collection. The net weights of the GCF samples were determined by subtracting the initial weights from those obtained, and they were stored at $-80^{\circ} \mathrm{C}$ until the laboratory evaluation process commenced.

\section{ELISA analysis}

MMP-3 levels were measured with Enzyme Linked Immuno Assay (ELISA) kits (KAC1541-HU MMP 3) as specified by the manufacturer (BioSource, Invitrogen Massachusetts, USA). These analyses were carried out at the Department of Immunology Laboratory. They were applied as follows: Eppendorf tubes containing frozen periopapers were defrosted by holding at room temperature for at least 20 minutes. 300 microlitres $(\mu \mathrm{l})$ of phosphate buffer saline $(\mathrm{Ph} 7)$ with $0.05 \%$ bovine albumin was added to each GCF sample and was stored for 24 hours in a refrigerator at $+4^{\circ} \mathrm{C}$. The GCF samples were nursed into periopapers, then diluted with phosphate buffer solution. $100 \mu$ of $1 \%$ BSA-PBS Tween buffer solution ( $\mathrm{pH}=7.4$ ) was added to each tube. Tubes were held for one hour at room temperature and then mixed horizontally at $+4^{\circ} \mathrm{C}$ for $20 \mathrm{~h}$. Following this procedure, the absorbent papers were removed from the Eppendorf tubes. After $24 \mathrm{~h}, 100 \mu \mathrm{l}$ from each solution was pulled with micropipettes to determine their MMP levels. These measurements were taken using an ELISA kit, applying the two-step sandwich enzyme method. All of the wells of the micro plaques present in the kit were covered with monoclonal MMP antibodies. Afterward, the MMP standards were diluted, as instructed by the ELISA kit's guide. The standards and GCF samples, measuring $100 \mu$, were then transported into each well with micropipettes. They were left for 4 hours for incubation. During this period, MMP bonded tightly to the antibodies. After incubation, the samples were washed in order to remove any unconnected parts. Then, $200 \mu$ of the secondary MMP monoclonal antibodies, which were connected with acetylcholinesterase, were added into the wells and left for 16 hours in order to let the secondary antibodies connect to MMPs. After the incubation, the samples were washed to remove excess secondary antibodies, and $200 \mu \mathrm{l}$ of chromogenic substrate was added to the solution. After 15 minutes, $\mathrm{H}_{2} \mathrm{SO}_{4}$ was added to halt the reaction. The enzymatic activity was read by ELISA at $405 \mathrm{~nm}$. The MMP results from the ELISA were obtained as concentrations measured in picograms $/ \mathrm{ml}(\mathrm{pg} / \mathrm{ml})$.

To analyze the amount of MMP per unit volume, the weights of the collected GCF samples needed to be converted into volume units. These GCF sample volumes were determined by measuring how much GCF the paper strips had absorbed. This process is explained below:

$0.05 \%$ bovine albumin was dissolved in PBS.

$100 \mu \mathrm{l}$ from this solution was added to each of the paper strips, each of which was then put into its own Eppendorf tube. They all were weighed before and after the process. This experiment was repeated 10 times for every weight. The average of these 10 measurements was used to obtain the unit volume corresponding to the unit weight. It was determined that $1 \mathrm{~g}$ corresponded to $990 \mu \mathrm{l}$. These raw data were then multiplied with the coefficients to form the real data.

\section{Detection of microbiological samples}

Microbiological samples were collected from one of the deepest periodontal pockets of each patient as well as 
from a region without attachment loss and without pocket formation. Before taking the samples using sterile paper points, supragingival plaque and debris were completely removed with cotton pellets.

The bacterial composition of the samples was semi-quantitatively determined with ParoCheck at the Department of Microbiology.

Each DNA sample was extracted and purified according to the standards of the manufacturer's instructions for the GenElute Bacterial Genomic DNA Kit (Sigma-Aldrich Co, St. Louis, MO, USA). The PCR amplification was carried out in a $20 \mu \mathrm{l}$ solution. The solution included: Master Mix $(18.8 \mu \mathrm{l})$, the sample DNA $(1 \mu \mathrm{l})$, and Taq DNA polymerase $(0.2 \mu \mathrm{l})$ (Fermentas UAB, Vilnius, Lithuania). The Master Mix was obtained with the ParoCheck kit (Greiner Bio-One GmbH, Frickenhausen, Germany) and contained dNTPs, a forward as well as a 5' end Cy5-labeled reversed primer, which universally targeted $16 \mathrm{~S}$ rDNA. The amplification was performed using a thermocycler (Eppendorf AG, Master Cycler Personel 22331, Hamburg, Germany), using the following temperature profiles and cycles: 1) pre-denaturation at $94^{\circ} \mathrm{C}$ for $1 \mathrm{~min}$; 2) 45 cycles: $95^{\circ} \mathrm{C}$ for $20 \mathrm{~s}$, stringent annealing at $60^{\circ} \mathrm{C}$ for $20 \mathrm{~s}$; 3) elongation $72^{\circ} \mathrm{C}$ for $30 \mathrm{~s}$; and 4) final elongation after 45 cycles: $72^{\circ} \mathrm{C}$ for $1 \mathrm{~min}$. Chip hybridization was carried out applying the guidelines of the manufacturer's instructions (ParoCheck, Greiner Bio-One $\mathrm{GmbH}$ ). Each slide was incubated for at least $5 \mathrm{~min}$ at $60^{\circ} \mathrm{C}$ in a saturated humid environment. Then, the hybridization buffer $(30 \mu \mathrm{l})$ and the target PCR product $(5 \mu \mathrm{l})$ were combined at room temperature, and $25 \mu \mathrm{l}$ of this solution was placed onto a slide, and a coverslip $(25 \mathrm{~mm} \times 25 \mathrm{~mm})$ was placed on top of it. The slide incubation continued for another $10 \mathrm{~min}$. Then, after removing the coverslip, the slide was treated with a buffer system (supplied with the ParoCheck kit). Using centrifugation, the surface was dried. Afterward, a CheckScanner (Greiner Bio-One $\mathrm{GmbH}$ ) was used to automatically generate results, which were then processed using the ParoReport software (supplied with the ParoCheck Kit, based on Gene Pixt, Axon Instruments Inc.). Using a semi-quanti- tative labeling scheme, the software interprets the control signals and restrains or releases the generation of an analysis report. The following labeling scheme was used to estimate the results (from weakest to strongest): negative, trace, low, moderate and high.

\section{Statistical analysis}

Means of PI, GI, PD and CAL were evaluated by ANOVA. These averages were compared with each other using the Bonferroni multiple variables test. Immunological and microbiological data were evaluated by the Kruskal-Wallis test. Statistically significant data were further evaluated using the Mann-Whitney $U$-test. The correlation of the data was determined using the Spearman test.

\section{Results}

$\mathrm{CP}$ and AgP groups showed significantly higher PI, GI, PD and CAL values compared to healthy subjects. The values of GI for the AgP group were slightly higher than those of the CP group, and the PI values were higher in the $\mathrm{CP}$ group compared to those of the AgP group, but these differences were not statistically significant. Both the $\mathrm{CP}$ and AgP groups had higher PD values compared to healthy subjects, and AgP patients had higher PD than the $\mathrm{CP}$ group, as expected. As for CAL means, the AgP and $\mathrm{CP}$ groups showed equally higher CAL values than the healthy group (Table 1).

When comparing all the data within the MMP-3 values, a significant difference was found $\left(\chi^{2}=19.853 ; p<0.001\right)$. Detailed analysis of the immunological data was carried out using the Mann-Whitney $U$-test (Table 1). The results were as follows: the AgP_D and AgP_H showed significantly higher MMP-3 values when compared both to the healthy sites of patients with chronic periodontitis $\left(\mathrm{CP}_{-} \mathrm{H}\right)$ and to the sites of the healthy control group $(\mathrm{H})(p<0.05)$. No statistically significant difference was observed between other groups $(p>0.05)$.

Table 1. Clinical parameters and MMP-3 levels according to the groups

\begin{tabular}{|c|c|c|c|c|c|c|}
\hline \multirow[t]{2}{*}{ Characteristic } & \multicolumn{2}{|c|}{$\begin{array}{c}\text { AgP } \\
(n=20)\end{array}$} & \multicolumn{2}{|c|}{$\begin{array}{c}\mathrm{CP} \\
(n=20)\end{array}$} & \multirow[t]{2}{*}{$\begin{array}{l}\text { Healthy } \\
(n=10)\end{array}$} & \multirow[t]{2}{*}{ Mean \pm SD } \\
\hline & $\begin{array}{l}\text { AgP_H } \\
(n=10)\end{array}$ & $\begin{array}{l}\text { AgP_D } \\
(n=10)\end{array}$ & $\begin{array}{c}\text { CP_H } \\
(n=10)\end{array}$ & $\begin{array}{c}\text { CP_D } \\
(n=10)\end{array}$ & & \\
\hline Plaque index & \multicolumn{2}{|c|}{$1.08 \pm 0.32^{\mathrm{a}}$} & \multicolumn{2}{|c|}{$1.32 \pm 0.39^{\mathrm{a}}$} & $0.72 \pm 0.26$ & $1.11 \pm 0.40$ \\
\hline Gingival index & \multicolumn{2}{|c|}{$1.09 \pm 0.30^{\mathrm{a}}$} & \multicolumn{2}{|c|}{$1.25 \pm 0.41^{\mathrm{a}}$} & $0.70 \pm 0.28$ & $1.07 \pm 0.40$ \\
\hline PD & \multicolumn{2}{|c|}{$3.80 \pm 0.55^{\mathrm{a}, \mathrm{b}}$} & \multicolumn{2}{|c|}{$3.06 \pm 0.65^{\mathrm{a}}$} & $1.03 \pm 0.46$ & $2.95 \pm 1.17$ \\
\hline CAL & \multicolumn{2}{|c|}{$4.54 \pm 0.93^{\mathrm{a}}$} & \multicolumn{2}{|c|}{$4.01 \pm 0.67^{\mathrm{a}}$} & $1.08 \pm 0.45$ & $3.63 \pm 1.51$ \\
\hline MMP-3 & $2.804^{\mathrm{c}}$ & $3.239^{c}$ & 3.050 & 3.131 & 1.075 & \\
\hline
\end{tabular}




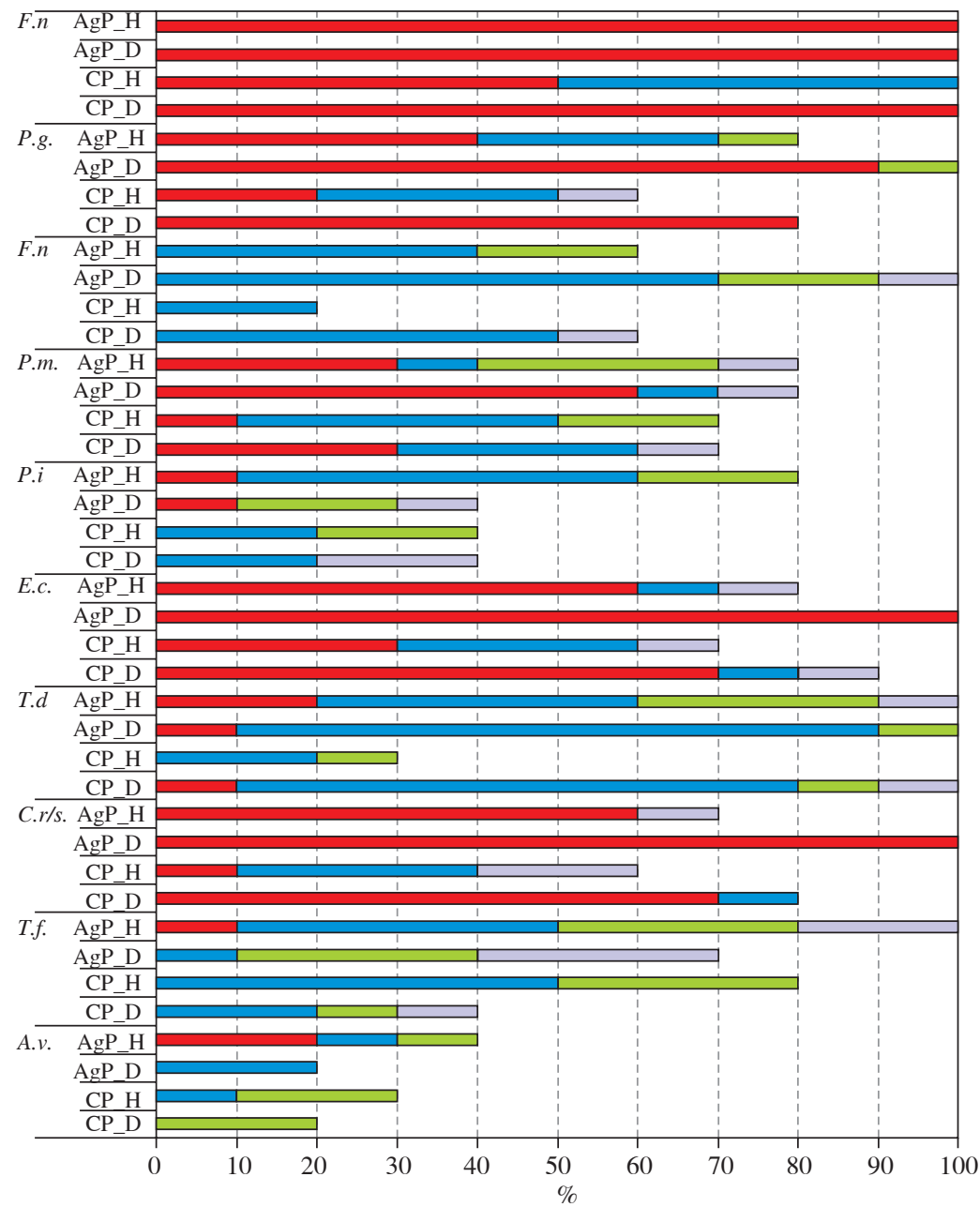

$\square$ High $\square$ Moderate $\square$ Low $\square$ Trace Negative

Fig. 1. Prevalence values of bacterial counts. Stacked bar chart of levels of bacterial species in the samples. Total length of each bar stack indicates the prevalence of bacterial species. Different colors indicate the percentages of samples containing different levels of the species. F.n. -F. nucleatum, P.g. - P. gingivalis, P.m. - P. micra, P.i. - P. intermedia, E.c. - E. corrodens, T.d. - T. denticola, C.r. - C. recta, T.f. - T. forsythia, A.v. - A. viscosus, A.a. - A. actinomycetemcomitans

The microbiological results from the AgP and CP samples were divided into four subgroups based on patient group and the health of the sample site: AgP_H, AgP_D, CP_H and CP_D. ParoCheck results were given as negative $(-)$, trace $((+))$, low $(+)$, moderate $(++)$ and high $(+++)$. Prevalence values for the bacteria can be found in Figure 1.

The bacterial count of $T$. forsythia from the AgP_D group showed significantly higher values compared to the three other groups. Likewise, T. forsythia obtained from the CP_D group were higher than those of the CP_H group. The number of $C$. recta obtained from the CP_H group were significantly lower than either Ag_D or Ag_H samples. As for T. denticola, bacterial levels of AgP_D were significantly higher than AgP_H or $\mathrm{CP}_{-} \mathrm{H}$. For $P$. gingivalis, the bacterial level of AgP_D was significantly higher than the $\mathrm{AgP} \_\mathrm{H}, \mathrm{CP} \_\mathrm{H}$, or $\mathrm{CP} \_\mathrm{D}$ samples. Likewise, levels from CP_D sites were significantly higher than those of CP_H $(p<0.05)$. In Ag_H, Ag_D, and CP_D sites, high levels of $F$. nucleatum were found and there was no difference among these groups $(p>0.05)$. In $\mathrm{CP} \_\mathrm{H}$, moderate levels of $F$. nucleatum were detected but compared to other groups these were significantly lower $(p<0.05)$.

The correlation of the microbiological data was evaluated with the Spearman test. T. denticola, T. forsythia, P. gingivalis, $C$. recta and $F$. nucleatum levels showed positive 
Table 2. Correlation of the periodontal pathogens

\begin{tabular}{|c|c|c|c|c|c|c|c|c|c|c|c|}
\hline & & A.a. & A.v. & T.f. & C.r. & T.d. & E.c. & P.i. & P.m. & P.g. & F.n. \\
\hline \multirow[t]{3}{*}{ A.a. } & Total & 1 & 0.054 & -0.043 & -0.101 & 0.081 & -0.073 & 0.023 & -0.113 & 0.013 & 0.19 \\
\hline & $\mathrm{AgP}$ & 1 & -0.128 & 0.016 & -0.257 & 0.067 & $-0.455^{\mathrm{a}}$ & 0.128 & 0.03 & 0.026 & \\
\hline & $\mathrm{CP}$ & 1 & 0.208 & -0.118 & 0.024 & 0.088 & 0.388 & -0.196 & -0.227 & -0.017 & 0.287 \\
\hline \multirow[t]{3}{*}{ A.v. } & Total & & 1 & $-0.360^{\mathrm{a}}$ & -0.112 & -0.26 & $0.430^{b}$ & -0.196 & -0.025 & $-0.349^{\mathrm{a}}$ & 0.015 \\
\hline & $\mathrm{AgP}$ & & 1 & $-0.520^{\mathrm{a}}$ & 0.087 & $-0.537^{\mathrm{a}}$ & 0.379 & -0.315 & -0.156 & $-0.451^{\mathrm{a}}$ & \\
\hline & $\mathrm{CP}$ & & 1 & -0.37 & -0.311 & -0.142 & $0.453^{\mathrm{a}}$ & -0.194 & -0.04 & -0.342 & -0.047 \\
\hline \multirow[t]{3}{*}{ T.f. } & Total & & & 1 & $0.645^{\mathrm{b}}$ & $0.927^{\mathrm{b}}$ & -0.281 & 0.051 & $0.430^{\mathrm{b}}$ & $0.855^{\mathrm{b}}$ & $0.448^{\mathrm{b}}$ \\
\hline & $\mathrm{AgP}$ & & & 1 & 0.352 & $0.982^{\mathrm{b}}$ & -0.291 & -0.089 & 0.325 & $0.751^{\mathrm{b}}$ & \\
\hline & $\mathrm{CP}$ & & & 1 & $0.773^{b}$ & $0.909^{b}$ & $-0.513^{\mathrm{a}}$ & 0.067 & $0.457^{\mathrm{a}}$ & $0.931^{\mathrm{b}}$ & $0.510^{\mathrm{a}}$ \\
\hline \multirow[t]{3}{*}{ C.r. } & Total & & & & 1 & $0.605^{\mathrm{b}}$ & 0.035 & 0.03 & 0.063 & $0.588^{\mathrm{b}}$ & $0.540^{\mathrm{b}}$ \\
\hline & $\mathrm{AgP}$ & & & & 1 & 0.326 & -0.008 & -0.002 & -0.222 & 0.232 & \\
\hline & $\mathrm{CP}$ & & & & 1 & $0.739^{\mathrm{b}}$ & -0.081 & -0.088 & 0.166 & $0.798^{\mathrm{b}}$ & $0.659^{\mathrm{b}}$ \\
\hline \multirow[t]{3}{*}{ T.d. } & Total & & & & & 1 & -0.285 & 0.005 & $0.444^{\mathrm{b}}$ & $0.858^{\mathrm{b}}$ & $0.509^{b}$ \\
\hline & $\mathrm{AgP}$ & & & & & 1 & -0.362 & -0.06 & 0.377 & $0.760^{\mathrm{b}}$ & \\
\hline & $\mathrm{CP}$ & & & & & 1 & -0.358 & -0.024 & $0.447^{\mathrm{a}}$ & $0.903^{b}$ & $0.633^{b}$ \\
\hline \multirow[t]{3}{*}{ E.c. } & Total & & & & & & 1 & -0.075 & -0.157 & -0.268 & 0.187 \\
\hline & $\mathrm{AgP}$ & & & & & & 1 & -0.097 & -0.128 & -0.217 & \\
\hline & $\mathrm{CP}$ & & & & & & 1 & -0.177 & -0.353 & $-0.461^{\mathrm{a}}$ & 0.172 \\
\hline \multirow[t]{3}{*}{ P.i. } & Total & & & & & & & 1 & 0.159 & 0.16 & 0.082 \\
\hline & $\mathrm{AgP}$ & & & & & & & 1 & 0.156 & 0.255 & \\
\hline & $\mathrm{CP}$ & & & & & & & 1 & -0.014 & 0.016 & 0 \\
\hline \multirow[t]{3}{*}{ P.m. } & Total & & & & & & & & 1 & $0.381^{\mathrm{a}}$ & $0.390^{\mathrm{a}}$ \\
\hline & $\mathrm{AgP}$ & & & & & & & & 1 & $0.464^{\mathrm{a}}$ & \\
\hline & $\mathrm{CP}$ & & & & & & & & 1 & 0.302 & 0.439 \\
\hline \multirow[t]{3}{*}{ P.g. } & Total & & & & & & & & & 1 & $0.364^{\mathrm{a}}$ \\
\hline & $\mathrm{AgP}$ & & & & & & & & & 1 & \\
\hline & $\mathrm{CP}$ & & & & & & & & & 1 & 0.425 \\
\hline
\end{tabular}

Table 3. Correlation of periodontal pathogens with probing depth and MMP-3 values

\begin{tabular}{ccccccccccc}
\hline & A.a. & A.v. & T.f. & C.r. & T.d. & E.c. & P.i. & P.m. & P.g. & F.n. \\
\hline PD & -0.142 & -0.257 & $0.530^{\mathrm{b}}$ & $0.483^{\mathrm{b}}$ & $0.476^{\mathrm{b}}$ & -0.166 & 0.190 & $0.367^{\mathrm{a}}$ & $0.434^{\mathrm{b}}$ & $0.399^{\mathrm{a}}$ \\
\hline MMP-3 & 0.123 & 0.011 & $0.385^{\mathrm{a}}$ & 0.229 & $0.314^{\mathrm{a}}$ & 0.043 & 0.100 & $0.349^{\mathrm{a}}$ & 0.248 & $0.329^{\mathrm{a}}$ \\
\hline
\end{tabular}

PD - probing depth, MMP-3 - matrix metalloproteinase 3, A.a. - A. actinomycetemcomitans, A.v. - A. viscosus, T.f. - T. forsythia, C.r. - C. recta, T.d. - T. denticola, E.c. - E. corrodens, P.i. - P. intermedia, P.m. - P. micra, P.g. - P. gingivalis, F.n. - F. nucleatum, ${ }^{a} p<0.05, n=50$, correlation is significant at the 0.05 level (2-tailed); ${ }^{b} p<0.01, n=50$, correlation is significant at the 0.01 level (2-tailed)

correlations with each other (Table 2). The relation between bacterial counts and probing depth are shown in Table 3.

The association between the microbiological and immunological data can be found in Table 3. T. denticola, T. forsythia, P. micra and F. nucleatum showed positive correlations with MMP-3 levels.

\section{Discussion}

It has been shown previously that the mean MMP-3 values of periodontitis sites are significantly higher compared to healthy sites and MMP-3 expression is probably initiated with bacterial stimuli [10]. The regulation of MMP-3, like the rest of MMPs, is governed by a com- 
plex mechanism, e.g. it is induced by molecules such as IL-1 $\beta$, TNF- $\alpha$ or reduced by COX-2 signaling pathways [11]. MMP-3 is considered to be one of the potential markers of periodontal destruction. Its values in patients with $\mathrm{CP}$ or AgP are higher and their increased GCF levels are correlated with the amount of periodontal tissue loss; it appears as high GI, PI, PD and CAL values in both types of periodontitis [12]. Although we can say that it plays a role in extracellular matrix degradation, it is not clear if MMP-3 is expressed more in certain stages of periodontal inflammation [13].

According to our results, MMP-3 levels in patients with $\mathrm{AgP}$ are statistically higher compared to the healthy sites of $\mathrm{CP}$ and $\mathrm{H}$ groups $(p<0.05)$. This result possibly reflects the inflammatory response complexity and heterogeneity. Regarding the distribution of pathogens across patient groups, as expected, the pathogen levels in $\mathrm{AgP}$ patients were the highest, followed by $\mathrm{CP}$ and then healthy patients. Unexpectedly, even the healthy sites in AgP patients showed higher levels of pathogens, especially red complex bacteria and $F$. nucleatum. In brief, all pockets in aggressive periodontitis patients are infected and demonstrate high MMP-3 levels, although the intensity of infection increases with pocket depth. These results are insufficient to explain how this marker influences the manifestation of periodontal disease, because the areas in patients with aggressive periodontitis which do not show any clinical sign of tissue destruction are still infected with periodontal pathogens and express higher MMP-3 values. If we consider previous research that demonstrated MMP3 and high pathogen levels, especially $P$. gingivalis, as a prognostic factor for the upcoming tissue loss [10, 14], accordingly we can presume that our currently healthy sites in AgP will be affected in time if not treated properly. Nonetheless, we can assert that MMP-3 is a molecule associated with aggressive periodontitis. The question why different areas in the same individual can demonstrate varied tissue loss is still to be answered.

It has been reported previously that $P$. gingivalis induced active MMP-3 production and collagen degradation of gingival fibroblasts [15], or the lipooligosaccharide of T. denticola increased MMP-3 mRNA expression [16]. According to our findings, MMP-3 levels are positively correlated with $T$. forsythia, $T$. denticola, $P$. micros and $F$. nucleatum. If these pathogens directly activate the expression of MMP-3, it is not of interest to this research.

It is known that $P$. gingivalis, $T$. forsythia and Prevotella, Fusobacterium, Campylobacter and Treponema levels are higher in patients with periodontitis; and as tissue transitions from healthy to inflamed with periodontitis, increases are observed in the levels of Actinomyces species and the so-called orange and red complex bacteria [17]. T. forsythia, C. recta, and $S$. noxia are identified as predominant species in active periodontal lesions, and these are the major bacteria which characterize the areas that are transitioning from healthy to diseased [18]. Clinical markers of periodontal disease, especially probing depth, are associated with red complex bacteria. $P$. gingivalis, $T$. forsythia and $T$. denticola have been detected in higher values in deeper pockets, and there is a mutual correlation among all of these bacteria [19, 20]. $P$. gingivalis can also be detected in healthy sites, but it has been shown that there can be a significant increase in the levels of these bacteria when probing depth values are higher than $4 \mathrm{~mm}$ [21]. In addition, C. recta, E. corrodens, $T$. denticola, $T$. sokranskii and oral spirochetes coinfect with $P$. gingivalis [22]. It has been proven that $T$. denticola counts are higher in the deep pockets of advanced periodontitis patients when compared to counts in healthy individuals or individuals with moderate disease [23]. In a study based on a Turkish sample population, values of all species except P. micra were found to be higher in patients with periodontitis when compared to healthy individuals. The frequency of A. actinomycetemcomitans, $P$. gingivalis and $C$. recta were also higher in patients with aggressive periodontitis than in healthy subjects [24]. Our study supports findings that red and orange complex species are directly related to periodontitis and the severity of periodontal lesions. As they demonstrate, $C$. recta, $P$. micra and $F$. nucleatum are positively correlated with probing depth, as are $T$. forsythia, $T$. denticola and $P$. gingivalis.

Due to our research, in the aggressive periodontitis group, it was observed that the three bacteria forming the red complex are positively correlated with each other. For the chronic periodontitis patient sample group, these data include both the red and orange complexes. The orange complex indicates a transition from a healthy profile to a diseased one [25], and there are slower destruction patterns in chronic periodontitis patients exhibiting the orange and red complex when compared to the rapid destruction patterns of aggressive periodontitis patients exhibiting mainly the red complex. Some studies have refuted the idea that $A$. actinomycetemcomitans is necessary for rapid destruction patterns, since they found that rapid destruction was present in areas where $A$. actinomycetemcomitans was absent. They found, however, that in those areas, red complex levels were higher than those of healthy individuals, supporting findings that the red complex drives tissue destruction [26, 27, 28]. In accordance with these previous studies, our results indicated that A. actinomycetemcomitans levels of AgP patients are not significantly higher than those of CP or healthy patients.

\section{Conclusions}

Our microbiological results correspond to the information that red and orange complex bacteria are involved in bacterial synergy and the severity of periodontitis. Rapid destruction patterns in aggressive periodontitis are linked to red complex bacteria, while in chronic periodontitis there is a slower shift from orange to red complex. 
Aggressive periodontitis patients show higher MMP-3 levels compared to periodontally healthy subjects and healthy areas of chronic periodontitis, and T. forsythia, $T$. denticola, $P$. micra and F. nucleatum values are positively correlated with MMP-3 levels. Our findings suggest that MMP-3 is a biomarker associated with generalized aggressive periodontitis.

\section{Acknowledgements}

This research is funded by Scientific Research Projects Committee of Istanbul University.

\section{The authors declare no conflict of interest.}

\section{References}

1. Cekici A, Kantarci A, Hasturk H, Van Dyke T (2014): Inflammatory and immune pathways in the pathogenesis of periodontal disease. Periodontol 2000 64: 57-80.

2. Teles R, Moss K, Preisser JS, et al. (2018): Patterns of periodontal disease progression based on linear mixed models of clinical attachment loss. J Clin Periodontol 45: 15-25.

3. Van Winkenhoff AJ, Loos BG, van der Reijden WA, van der Welden U (2002): Porphyromonas gingivalis, Bacteriodes forsythus and other putative periodontal pathogens in subjects with and without periodontal destruction. J Clin Periodontol 29: 1023-1028.

4. Grisi MF, Novaes AB, Ito IY, Salvador SL (1998): Relationship between clinical probing depth and reactivity to the BANA test of samples of subgingival microbiota from patients with periodontitis. Braz Dent J 9: 77-84.

5. Ingman T, Tervahartiala T, Ding Y, et al. (1996): Matrix metalloproteinases and their inhibitors in gingival crevicular fluid and saliva of periodontitis patients. J Clin Periodontol 23: 1127-1132.

6. Visse R, Nagase H (2003): Matrix Metalloproteinases and Tissue Inhibitors of Metalloproteinases Structure, Function, and Biochemistry. Circ Res 92: 827-839.

7. Armitage GC (1999): Development of a classification system for periodontal diseases and conditions, Ann Periodontol 4: $1-6$.

8. Silness J, Loe H (1964): Periodontal disease in pregnancy. II. Correlation between oral hygiene and periodontal condition. Acta Odontol Scand 22: 121-135.

9. Loe H, Silness J (1963): Periodontal disease in pregnancy. Acta Odontol Scand 21: 533-551.

10. Alpagot T, Bell C, Lundergan W, et al. (2001): Longitudinal evaluation of GCF MMP-3 and TIMP-1 levels as prognostic factors for progression of periodontitis. J Clin Periodontol 28: 353-359.

11. Domeij H, Yucel-Lindberg T, Modéer T (2002): Signal pathways involved in the production of MMP-1 and MMP-3 in human gingival fibroblasts. Eur J Oral Sci 110: 302-306.

12. Toyman U, Tüter G, Kurtis B, et al. (2015): Evaluation of gingival crevicular fluid levels of tissue plasminogen activator, plasminogen activator inhibitor 2, matrix metalloproteinase-3 and interleukin 1-b in patients with different periodontal diseases. J Periodont Res 50: 44-51.
13. Ejeil AL, Igondjo-Tchen S, Ghomrasseni S, et al. (2003): Expression of Matrix Metalloproteinases (MMPs) and Tissue Inhibitors of Metalloproteinases (TIMPs) in Healthy and Diseased Human Gingiva. J Periodontol 74: 188-195.

14. Kakuta E, Nomura Y, Morozumi T, et al. (2017): Assessing the progression of chronic periodontitis using subgingival pathogen levels: a 24-month prospective multicenter cohort study. BMC Oral Health 17: 46.

15. Zhou J, Windsor LJ (2006): Porphyromonas gingivalis affects host collagen degradation by affecting expression, activation, and inhibition of matrix metalloproteinases. J Periodontal Res 41: 47-54.

16. Choi BK, Lee HJ, Kang JH, et al. (2003): Induction of osteoclastogenesis and matrix metalloproteinase expression by the lipooligosaccharide of Treponema denticola. Infect Immun 71: 226-233.

17. Ximénez-Fyvie LA, Haffajee AD, Socransky SS (2000): Comparison of the microbiota of supra- and subgingival plaque in health and periodontitis. J Clin Periodontol 27: 648-657.

18. Tanner A, Maiden MF, Macuch PJ, et al. (1998): Microbiota of health, gingivitis, and initial periodontitis. J Clin Periodontol 25: 85-98.

19. Mineoka T, Awano S, Rikimaru T, et al. (2008): Site-specific development of periodontal disease is associated with increased levels of Porphyromonas gingivalis, Treponema denticola, and Tannerella forsythia in subgingival plaque. J Periodontol 79: 670-676.

20. Topcuoglu N, Külekci G (2015): 16S rRNA based microarrey analysis of ten periodontal bacteria in patients with different forms of periodontitis. Anaerobe 35 (Pt A): 35-40.

21. Kojima T, Yasui S, Ishikawa I (1993): Distribution of Porphyromonas gingivalis in adult periodontitis patients. J Periodontol 64: 1231-1237.

22. Riviere GR, Smith KS, Carranza N Jr, et al. (1996): Associations between Porphyromonas gingivalis and oral treponemes in subgingival plaque. Oral Microbiol Immunol 11: 150-155.

23. Simonson LG, McMahon KT, Childers DW, Morton HE (1992): Bacterial synergy of Treponema denticola and Porphyromonas gingivalis in a multinational population. Oral Microbiol Immunol 7: 111-112.

24. Doğan B, Antinheimo J, Cetiner D, et al. (2003): Subgingival microflora in Turkish patients with periodontitis. J Periodontol 74: 803-814.

25. Socransky SS, Haffajee AD, Cugini MA, et al. (1998): Microbial complexes in subgingival plaque. J Clin Periodontol 25: 134-144.

26. López NJ, Mellado JC, Leighton GX (1996): Occurrence of Actinobacillus actinomycetemcomitans, Porphyromonas gingivalis and Prevotella intermedia in juvenile periodontitis. J Clin Periodontol 23: 101-105.

27. Takeuchi Y, Umeda M, Sakamoto M, et al. (2001): Treponema socranskii, Treponema denticola, and Porphyromonas gingivalis are associated with severity of periodontal tissue destruction. J Periodontol 72: 1354-1363.

28. Yano-Higuchi K, Takamatsu N, He T, et al. (2000): Prevalence of Bacteroides forsythus, Porphyromonas gingivalis and Actinobacillus actinomycetemcomitans in subgingival microflora of Japanese patients with adult and rapidly progressive periodontitis. J Clin Periodontol 27: 597-602. 